\title{
EFFECT OF DILUTION WITH DIFFERENT FLUIDS ON BLOOD COAGULATION
}

\section{Grzegorz Wilhelm ${ }^{1}$, Dorota Siwicka-Gieroba', Magdalena Bielacz', Hubert Kolano ${ }^{3}$, Ziemowit Rzecki ${ }^{1}$, Wojciech Dabrowski ${ }^{1}$}

1. Department of Anaesthesiology and Intensive Therapy Medical University of Lublin, Poland 2. Institute of Tourism and Recreation, State Vocational College of Szymon Szymonowicz, Zamość, Poland 3. Regional Hospital in Nisko, Poland.

Perioperative blood dilution may affect increasing risk of perioperative bleeding. Some experimental studies have documented significant increase in APTT, PT, INR following hydroxyethyl starch (HES) and normal saline infusion [1,2]. Unfortunately the effect of blood dilution with balanced crystalloids and gelatin on coagulation times (APTT and PT) has not been thoroughly investigated .

\section{The aim of this study was to analyse an in vitro effect of isovolaemic blood dilution on coagulation} variables.

Material and methods: Blood samples from 30 healthy voluntaries at the volume of 10 $\mathrm{mL}$ were diluted with crystalloid solution (Sterifundin ${ }^{\circledR} \quad$ ISO, Braun), gelatin (Gelaspan $\AA$, Braun), and hydroxyethyl starch (Tetraspan ${ }^{\circledR}$, Braun). According to degree of dilution, samples were randomized using a concealed envelope method into three equal groups: diluted to $25 \%, 35$ and $45 \%(\mathrm{n}=10)$. APTT, PT and international normalized ration INR were assessed in samples just before dilution (baseline) and after dilution.

\section{Co \\ pi}

p)

vitro, coagulation spectacularly hydroxyethyl samples. The greatest changes in PT and INR caused blood dilution to $25 \%$.

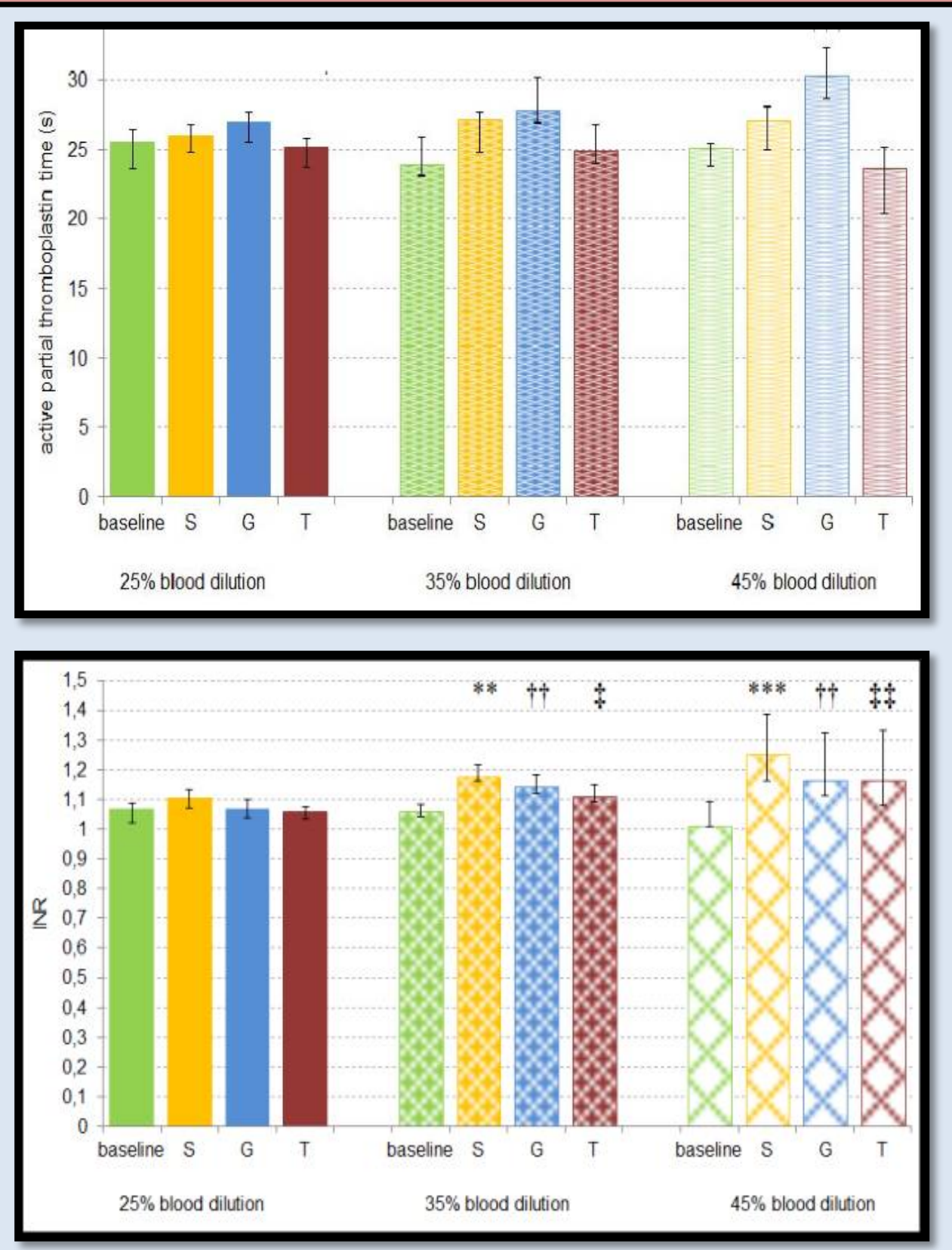

Figure 2. Effect of blood dilution with Sterofundin ${ }^{\circledR}$ (S), Gelaspan ${ }^{\circledR} \quad(\mathrm{G})$ and Tetraspan ${ }^{\circledR}$ (T) on international normalized ratio (INR). $25 \%$ blood dilution: baseline vs $\mathrm{S}:-\mathrm{p}<0.01$, $\mathrm{S}$ vs $\mathrm{G}:-\mathrm{p}<0.01$, $\mathrm{S}$ vs T: $\mathrm{p}<0.01 .35 \%$ blood dilution: baseline vs $\mathrm{S}$ : $\mathrm{p}<0.01$, baseline vs G: $-\mathrm{p}<0.01$, baseline vs T: $-\mathrm{p}$ $<0.01$, S vs T: - p $<0.01$, G vs T: - p $<0.01 .45 \%$ blood dilution: baseline vs $\mathrm{S}:-\mathrm{p}<0.01$, baseline vs G: $-\mathrm{p}<0.01$, baseline vs $\mathrm{T}:-\mathrm{p}<0.01$. ** $\mathrm{p}<0.01-$ differences in prothrombin time between $25 \%$ and

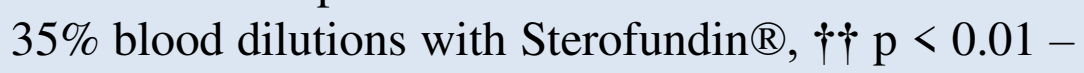
differences in prothrombin time between $25 \%$ and $45 \%$ blood dilutions with Gelaspan ${ }^{\circledR}, \ddagger \mathrm{p}<0.05$ and $\$ \mathrm{p}<0.01$ - differences in prothrombin time between $25 \%$ and $45 \%$ blood dilutions with Tetraspan ${ }^{\circledR}$
Figure 1. Effect of blood dilution with Sterofundin ${ }^{\circledR}(\mathrm{S})$, Gelaspan $^{\circledR} \quad(G)$ and Tetraspan $^{\circledR}$ (T) on active partial thromboplastin time (APTT). $25 \%$ blood dilution: baseline vs $\mathrm{G}:-p<0.05$, S vs $\mathrm{G}-\mathrm{p}<0.05$, S vs T: $p<0.01$, G vs T: $p$ $<0.01$. $35 \%$ blood dilution: baseline vs $S:-p<0.05$, baseline vs $G:-p<0.01$, S vs G: $p<0.01$, S vs T: $-p<0.01$, $G$ vs $T:-p<0.01 .45 \%$ blood dilution: baseline vs $G-p<$ 0.01 , baseline vs $T-p<0.05$, S vs $G p<0.05$, S vs $T p<$ $0.01, G$ vs $T p<0.01$. +t+ $p<0.001$ - differences in prothrombin time between $25 \%$ and $45 \%$ blood dilutions with Gelaspan ${ }^{\circledast}$.

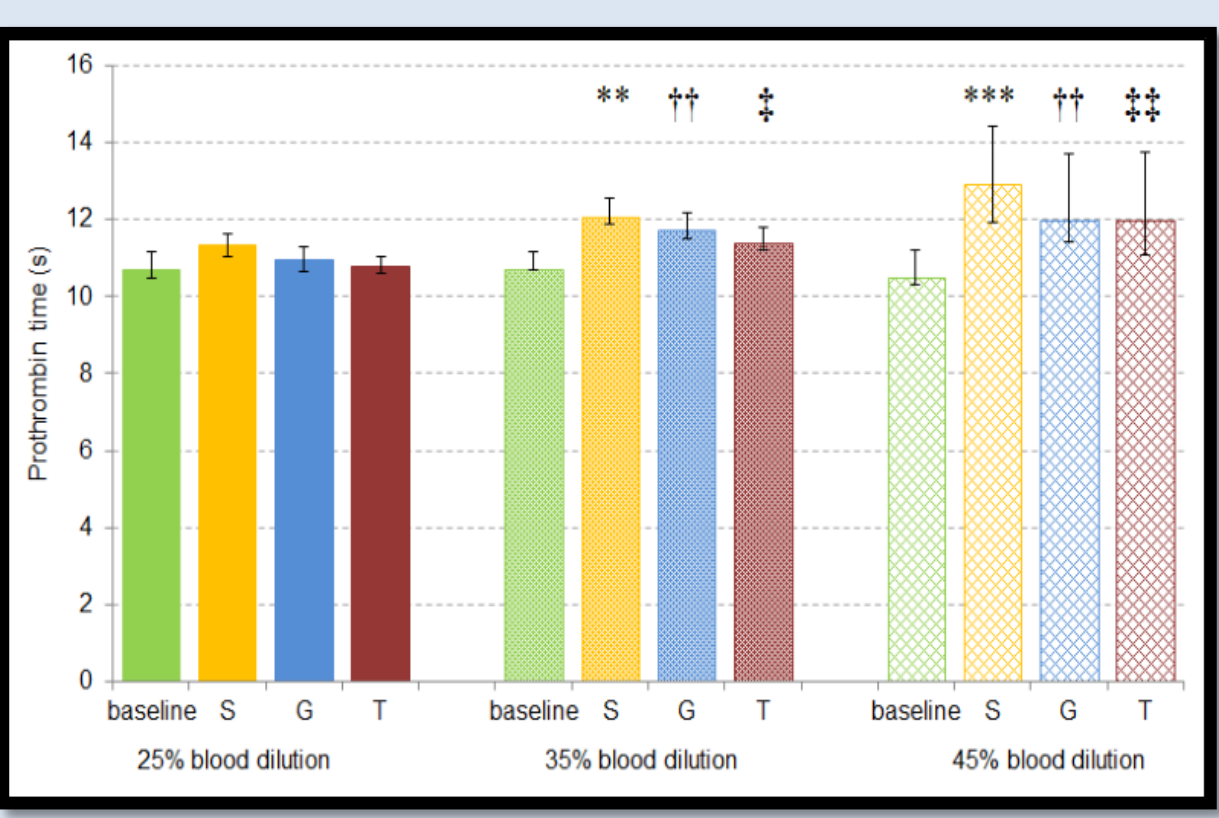

Figure 3. Effect of blood dilution with Sterofundin ${ }^{\circledR}(\mathrm{S})$, Gelaspan ${ }^{\circledR}(\mathrm{G})$ and Tetraspan ${ }^{\circledR}(\mathrm{T})$ on prothrombin time (PT). $25 \%$ blood dilution: baseline vs S: $-\mathrm{p}<0.01$, $\mathrm{S}$ vs G: $-\mathrm{p}<0.01$, $\mathrm{S}$ vs T: $\mathrm{p}<0.01 .35 \%$ blood dilution: baseline vs S: $-\mathrm{p}<0.01$, baseline vs G: $-\mathrm{p}<0.01$, baseline vs $\mathrm{T}:-\mathrm{p}<$ $0.01, \mathrm{~S}$ vs $\mathrm{T}:-\mathrm{p}<0.01, \mathrm{G}$ vs $\mathrm{T}:-\mathrm{p}<0.01 .45 \%$ blood dilution: baseline vs $\mathrm{S}:-\mathrm{p}<0.01$, baseline vs $\mathrm{G}:-\mathrm{p}<0.01$, baseline vs $\mathrm{T}:-\mathrm{p}<0.01$. ** $\mathrm{p}<0.01-$ differences in prothrombin time between $25 \%$ and $35 \%$ blood dilutions

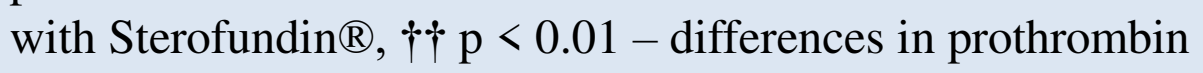
time between $25 \%$ and $45 \%$ blood dilutions with Gelaspan ${ }^{\circledR}, \ddagger \mathrm{p}<0.05$ and $\sharp \mathrm{p}<0.01$ - differences in prothrombin time between $25 \%$ and $45 \%$ blood dilutions with Tetraspan ${ }^{\circledR}$

1) Griego-Valles M, Buriko Y, Prittie JE, Fox PR. An in vitro comparison of the effects of voluven (6\% hydroxyethyl starch $130 / 0.4)$ and hespan (6\% hydroxyethyl starch 670/0.75) on measures of blood coagulation in canine blood. J Vet Emerg Crit Care. 2017; 27(1): $44-51$ doi. $10.1111 /$ vec. 12541.

2) Weiss G, Lison S, Spannagl M, Heindl B. Expressiveness of global coagulation parameters in dilutional coagulopathy. Br J Anaesth. 2010; 105(4): 429 - 36 doi. 10.1093/bja/aeq199. 